\title{
Optic nerve avulsion due to forced rotation of the globe by a snooker cue
}

Department of Ophthalmology, Oxford Eye Hospital, Oxford P G Hykin

I D Gardner

S M Wheatcroft

Correspondence to:

Mr P G Hykin, FRCS, Oxford Eye Hospital, Walton Street, Oxford OX2 6AN.

Accepted for publication 8 March 1990

P G Hykin, I D Gardner, S M Wheatcroft

\begin{abstract}
We report a case of partial avulsion of the optic nerve caused by sudden rotation of the globe due to a snooker cue injury. Minimal direct ocular trauma occurred. This case supports the belief that sudden rotation of the globe is the major mechanism of optic nerve avulsion. We include the first results of ultrasound examination that demonstrate optic nerve injury in such a case and believe that, in conjunction with fluorescein angiography and computerised tomography, it is important in the full evaluation of such cases.
\end{abstract}

Optic nerve avulsion is an uncommon injury that has been reported following major head trauma ${ }^{1}$ and, less frequently, after pointed but blunt nonpenetrating orbital injuries with minimal ocular trauma. ${ }^{2}$ The method of avulsion in the latter group is thought to result from either sudden rapid rotation of the globe, ${ }^{3}$ or a sudden rise in intraocular pressure forcing the optic nerve posteriorly along its sheath, ${ }^{4}$ or by the object causing anterior displacement of the globe as it enters the orbit, avulsing the nerve from the eye. ${ }^{4}$ If total avulsion of the nerve occurs, the eye is completely blind. Varying degrees of visual loss and altitudinal field defects may follow partial avulsions. ${ }^{5}$ Investigation of these cases has been by clinical evaluation, fluorescein angiography, and computerised tomography. ${ }^{6}$ Ultrasound has previously been unhelpful in demonstrating actual optic nerve damage. ${ }^{7}$ There is no effective treatment.

\section{Case report}

A 22-year-old man presented with sudden loss of vision in the left eye. He had been balancing a snooker cue, tip downward on the palm of his

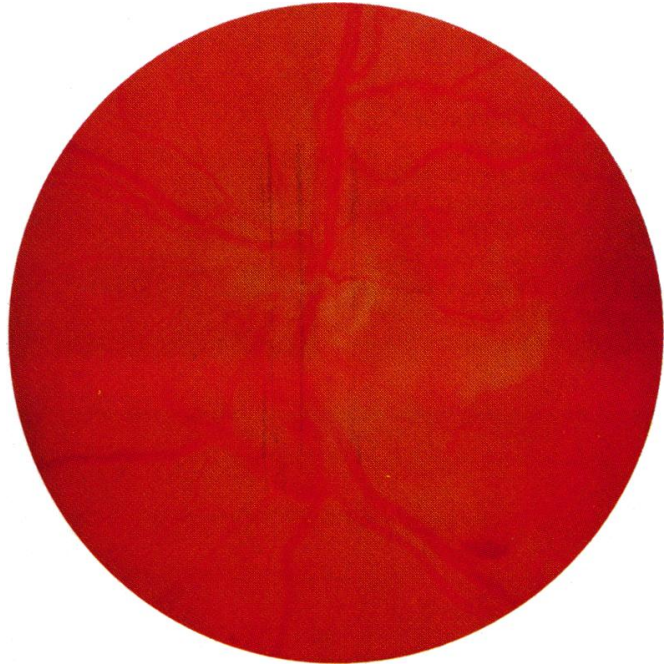

Figure 1 Left inferotemporal optic nerve avulsion with hold-up of axoplasmic flow in the corresponding retina.

Vitreous haemorrhage is present.

hand, immediately above his face. He recalled it slipping and hitting his left eye and was immediately aware of loss of his left upper visual field. There was no previous history of ocular disease.

On examination the left visual acuity was counting fingers, and no Ishihara colour plates were seen. There was a left afferent pupillary defect. There was a small corneal abrasion at the limbus in the 12 o'clock position and a $1 \mathrm{~cm}$ horizontal tear of the bulbar conjunctiva approximately $5 \mathrm{~mm}$ superior to this. Occasional red blood cells were seen in the anterior chamber. The intraocular pressure was $16 \mathrm{mmHg}$. There were mild vitreous and peripapillary haemorrhages. At least the inferotemporal portion of the optic nerve was avulsed, with hold up of axoplasmic flow in the corresponding retina thought to be secondary to direct avulsion of nerve fibres,

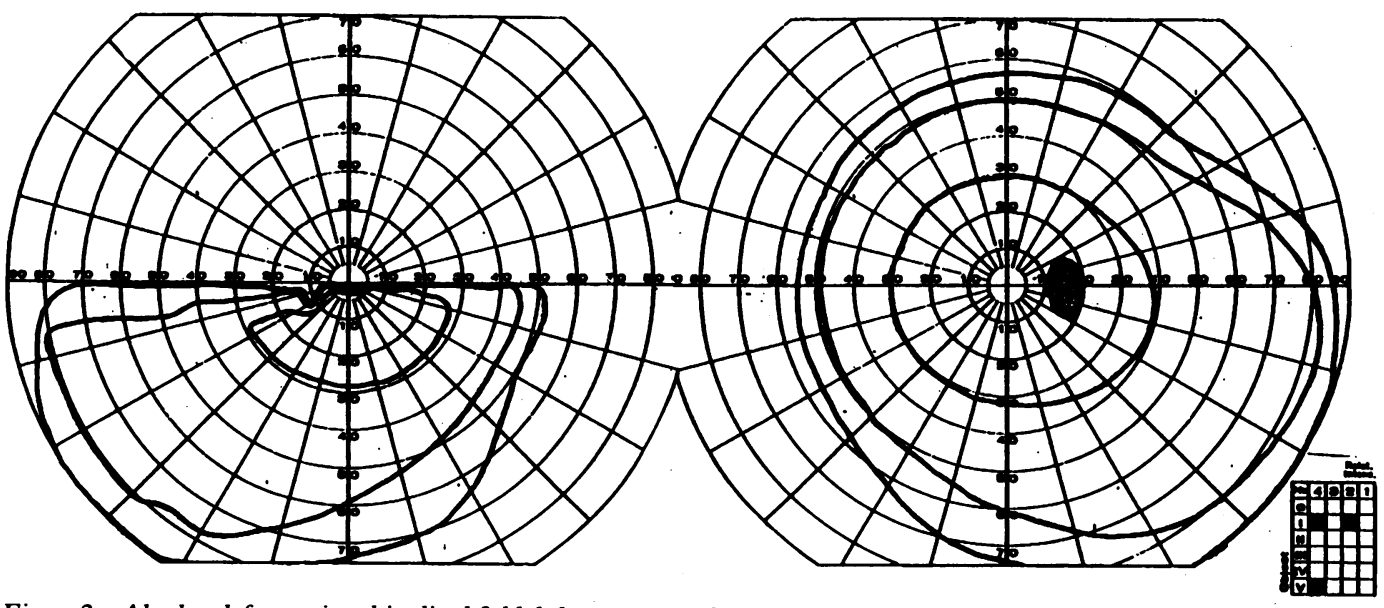

Figure 2 Absolute left superior altitudinal field defect at one week. 

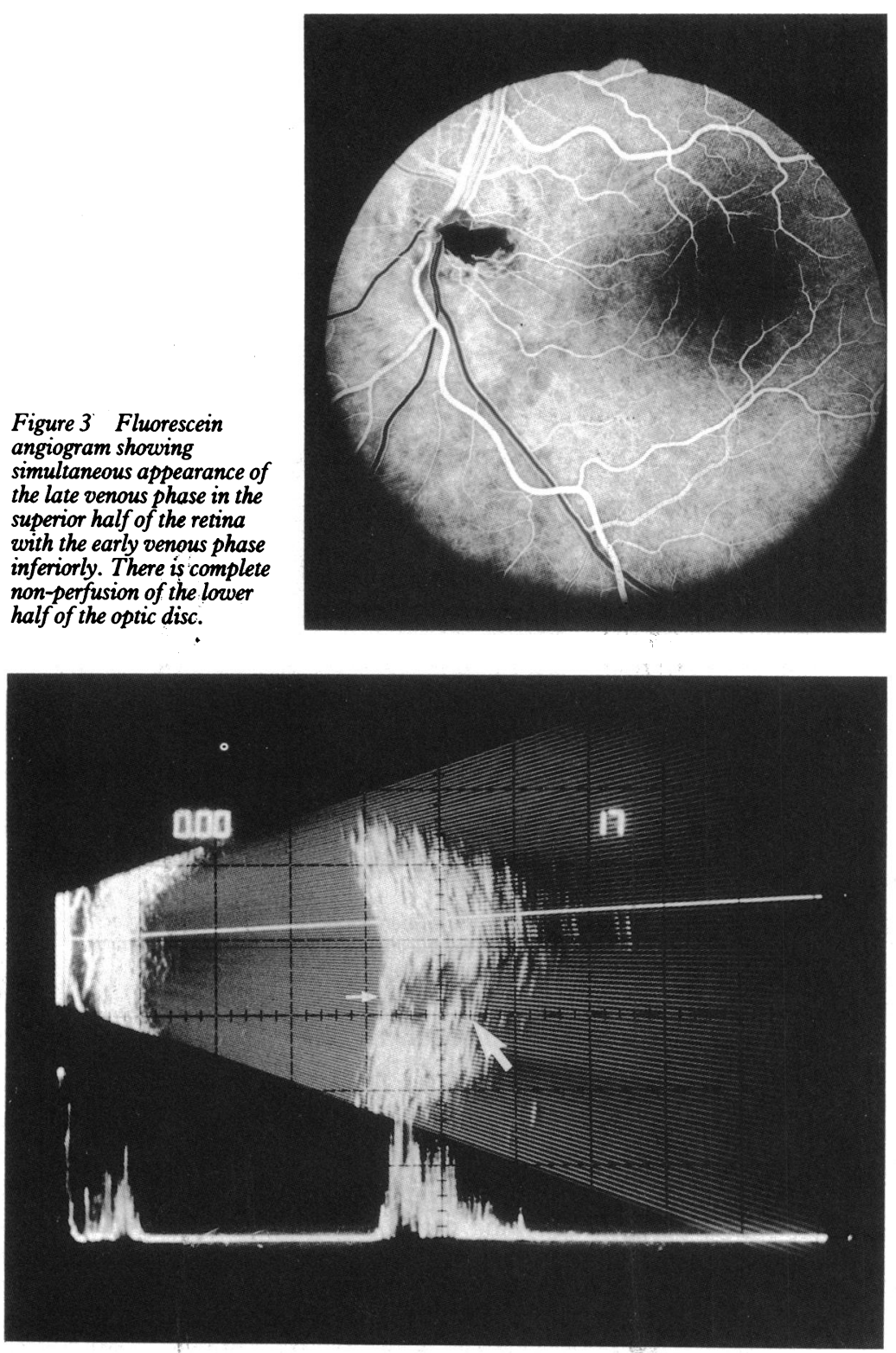

Figure 4

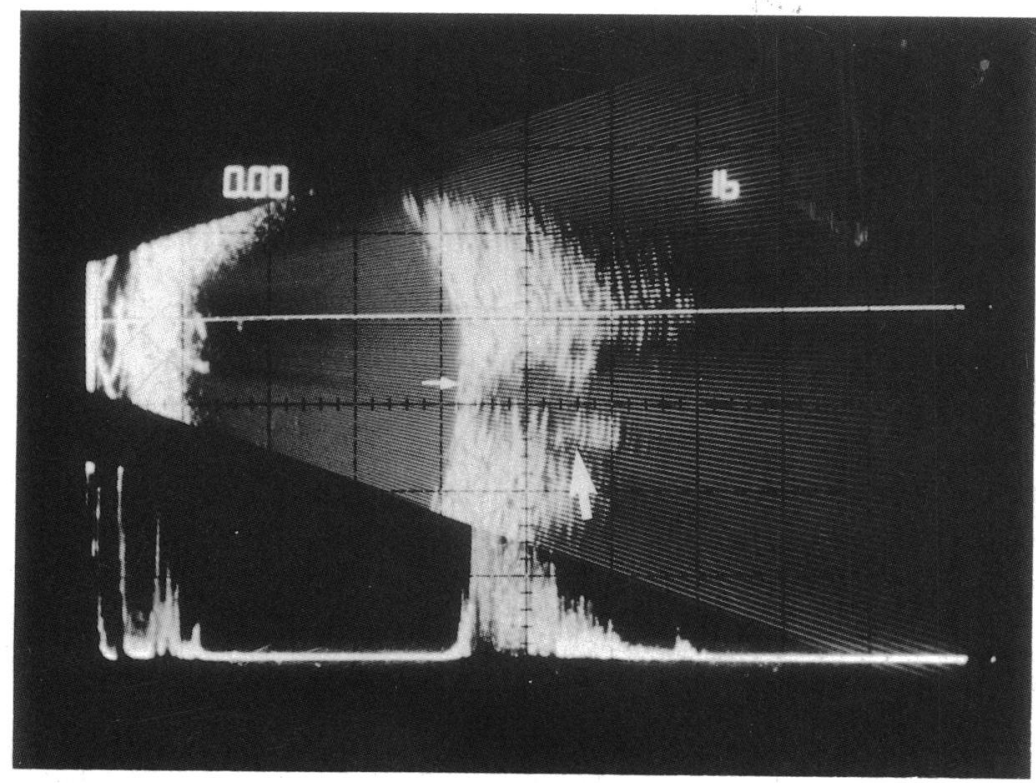

Figure 5

Figures 4 and 5 Vertical (Fig 4) and horizontal (Fig 5) B-scan ultrasonography. There is optic nervehead signal attenuation (small arrows) but increased signal arising from the anterior third of the optic nerve (large arrows). which we believe to be previously unreported. Optic disc oedema was present superiorly (Fig 1). A left superior altitudinal field defect to confrontation was present and was confirmed on formal perimetry some days later, after the vitreous haemorrhage had cleared (Fig 2). The right eye was normal.

Fluorescein angiography at six weeks showed delayed filling of the inferior retinal circulation as evidenced by the simultaneous appearance of the late venous phase in the superior half of the retina with the early venous phase inferiorly. In addition there was complete non-perfusion of the lower half of the optic disc, with mild late fluorescein leakage superiorly due to residual disc oedema (Fig 3).

At the same time, an ultrasound B scan demonstrated loss of signal attenuation at the optic disc (Figs 4, 5, small arrow), confirming the clinical picture of partial optic nerve avulsion. Posterior to this the ultrasound showed greater signal attenuation than normal, indicative of ingrowth of glial scar tissue into the damaged optic nerve (Figs 4, 5, large arrow). Forty-eight hours after injury the left visual acuity had improved to $6 / 9$. At six weeks the acuity was $6 / 9$, and the superior altitudinal field defect remained. Avulsion and pallor of the inferior half of the optic nerve head were clearly visible. Full thickness retinal striae, seen temporal to the optic disc, were thought to represent the retinal response to compressive injury (Fig 6).

\section{Discussion}

This patient presented with an avulsion of the inferior half of the left optic nerve. It seems likely that the injury was caused by the tip of the snooker cue forcefully rotating the globe superiorly, as evidenced by the site of impact. This resulted in the optic nerve being violently rotated downwards and forwards. In this position maximum stress would have been conveyed to the inferior fibres within the optic nervehead, leading to their avulsion from the globe. This agrees with the previously held view that damage to optic nerve fibres occurs in the leading edge of the nerve in the direction of globe rotation. ${ }^{3}$

Several other mechanisms have been proposed to account for optic nerve avulsion in similar cases. A sudden rise in intraocular pressure with resultant posterior displacement of the nerve within its sheath has been suggested. ${ }^{4}$ Marked damage to the optic nerve, however, in the absence of significant intraocular damage, seems unlikely, It has also been suggested that if a pointed instrument penetrates the orbit the globe may be momentarily displaced forwards, causing avulsion of the optic nerve. This again seems unlikely, as one would predict accompanying damage to the extraocular muscles in such a situation, which is not a consistent finding. ${ }^{+}$

The results of fluorescein angiography have been described in only a few cases of optic nerve avulsion and have been normal, ${ }^{8}$ showed an absence of the retinal circulation, ${ }^{+}$or showed delayed venous filling. ${ }^{9}$ Vascular shunts have been described between the peripapillary choroidal and retinal circulations. ${ }^{10}$ Our case had 


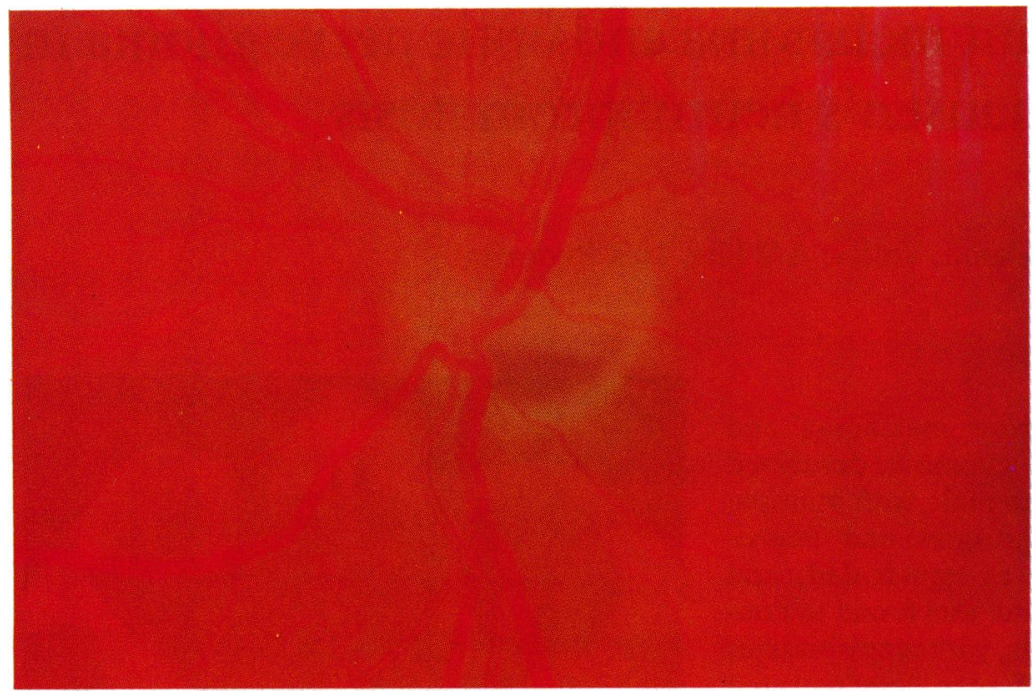

Figure 6 The left optic disc at six weeks demonstrating avulsion and pallor of the inferior half of the optic nerve, full thickness retinal striae temporal to the disc and inferior retinal vascular attenuation. Mild residual vitreous haemorrhage remains.

delayed filling of the circulation to the lower half of the retina and, as reported once before," complete absence of capillary filling to the inferior half of the optic disc. This suggests compromise of the inferior retinal circulation and occlusion of the blood supply to the lower half of the optic nervehead. This could well be explained by the stripping off of the recurrent pial branches of the paraoptic short posterior ciliary arteries which lead on to form the circle of Zinn-Haller. ${ }^{12}$ We believe this vascular damage to have occurred at the time of injury and to explain the immediate sudden onset of the superior altitudinal field defect. This vascular insufficiency was still present at six weeks (Fig 3).
The findings on B-scan ultrasonography of an attenuated optic nervehead signal and additional echoes arising from within the optic nerve, suggesting the ingrowth of glial scar tissue,,$^{13}$ have not been previously reported in optic nerve avulsion, ${ }^{5}$ though orbital haemorrhage has been demonstrated by ultrasonography in a few cases. ${ }^{7}$ We do not believe these optic nerve changes are specific to this condition but suggest that B-scan ultrasonography is an important part of the full investigation of such cases, especially if, as is frequently the case, vitreous haemorrhage obscures the optic disc.

We thank Professor A J Bron for permission to report this case, and Mr P Parker for photographic assistance.

1 Nau HE, Gerhard L, Foerster M, et al. Optic nerve trauma: clinical, electrophysiological and histological remarks. Acta Neurochir Wien 1987; 89: 16-27.

2 Chow AY, Goldberg MF, Frenkel M. Evulsion of the optic nerve in association with basketball injuries. Ann Ophthalmol 1984; 16: 35-7.

3 Williams DF, Williams GA, Abrams GW, et al. Evulsion of the retina associated with optic nerve avulsion. Am f Ophthalmol 1987; 104: 5-9.

4 Sanborn GE, Gonder JR, Goldberg RE, Benson WE. Evulsion of the optic nerve: a clinicophathological study. Can $\mathcal{F}$ Ophthalmol 1984; 19: 10-6

5 Rosenberg PN, Stasior OB. Optic nerve evulsion and transection. Adv Ophthalmic Plast Reconstruct Surg 1987; 6: 63-9.

6 Chang M, Eifrig DE. Optic nerve avulsion. Arch Ophthalmol 1987; 105: 322-3.

7 Coleman DJ, Lizzi L, Lack RL Ultrasonography of the eye and orbit. Philadelphia: Lea and Febiger, 1977: 345.

8 Park JH, Frenkel M, Dobbie JG, Choromokos E, et al.Evulsion of the optic nerve. Am f Ophthalmol 1971; 72: 969-71.

9 Hart JCD, Pilley SFJ. Partial evulsion of the optic nerve:

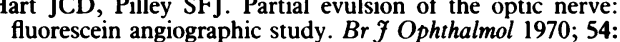
781-5.

10 Archer DB, Canavan YM. Contusional injuries of the distal optic nerve. Trans Ophthalmol Soc NZ 1983; 35: 14-23.

11 Zinn KM, Kirban EH. Partial avulsion of the optic nervehead secondary to local trauma. Mt Sinai f Med (NY) 1989; 51 629-32.

12 Olver JM, Spalton DJ, McCartney ACE. Microvascular study of the retrolaminer optic nerve in man. Eye $1990 ; 4: 7-24$.

13 Skalka HW, Kline LB. Comparative value of ultrasound and CT scanning in orbital optic nerve evaluation. In: Herkes HE, ed. Ophthaimic ultrasonography proceedings of 9th
SIDUO Congress. Doc Ophthalmol Proc Ser 1982;38:365-6. 